Check for updates

Cite this: RSC Adv., 2020, 10, 14025

\title{
Bioderived ionic liquid-based pretreatment enhances methane production from Agave tequilana bagasse $\uparrow$
}

\begin{abstract}
José A. Pérez-Pimienta, (DD a José P. A. Icaza-Herrera, ${ }^{\mathrm{b}}$ Hugo O. Méndez-Acosta, ${ }^{\mathrm{b}}$

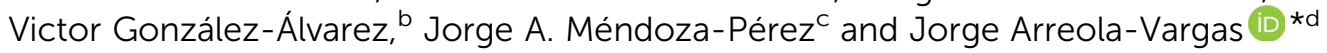

In recent years, bioderived ionic liquids have gained attention as a new promising approach for lignocellulosic biomass pretreatment. In this work, Agave tequilana bagasse (ATB), an attractive bioenergy feedstock in Mexico, was pretreated with a bioderived ionic liquid (cholinium lysinate) for the first time. Optimization of the pretreatment conditions, in-depth biomass characterization and methane generation via anaerobic digestion are the main contributions of this work. The results indicated optimized pretreatment conditions of $124{ }^{\circ} \mathrm{C}, 205 \mathrm{~min}$ and $20 \%$ solids loading by applying a central composite design. The optimized pretreated ATB was able to produce an elevated sugar yield of $51.4 \mathrm{~g}$ total sugars per g ATB due to their high delignification (45.4\%) and changes in their chemical linkages although an increase in cellulose crystallinity was found $(0.51$ untreated vs. 0.62 pretreated). Finally, the mass balance showed that $38.2 \mathrm{~kg}$ glucose and $13.1 \mathrm{~kg}$ xylose were converted into $12.5 \mathrm{~kg}$ of methane per $100 \mathrm{~kg}$ of untreated ATB, representing $86 \%$ of the theoretical methane yield and evidencing the potential of this biorefinery scheme.
\end{abstract}

Received 27th February 2020

Accepted 30th March 2020

DOI: 10.1039/d0ra01849j

rsc.li/rsc-advances

lignin and hemicelluloses that embeds the cellulose fiber

\section{Introduction}

Increased industrialization and deforestation combined with the enhanced price of conventional fuels have led to depletion of feedstock for first generation biofuels (such as: sugars, starch, animal fats, and vegetable oils). ${ }^{1}$ On the other hand, lignocellulosic biomass (LCB) is the most available carbon resource generated on earth and is considered a safe alternative to petroleum-based fuels, equivalent to zero emission and a renewable energy resource for the production of biofuels and bioproducts. $^{2}$

In recent years, Agave has emerged as a potential bioenergy feedstock in Mexico due to their advantageous features (e.g. low water requirements, high productivity up to 44 ton per ha per year, and drought resistance) with an estimated productivity of $11.4 \times 10^{5}$ tons in 2018 for Agave tequilana, from which approximately $40 \%$ were converted to bagasse. ${ }^{3-5}$ Agave bagasse as any other LCB is constituted of a cross-linking matrix of

${ }^{a}$ Department of Chemical Engineering, Universidad Autónoma de Nayarit, Tepic, Mexico

${ }^{b}$ Departamento de Ingeniería Quimica, CUCEI-Universidad de Guadalajara, Guadalajara, Jalisco, Mexico

${ }^{c}$ Department of Engineering in Environmental Systems, Instituto Politécnico Nacional, Mexico City, Mexico

${ }^{d}$ División de Procesos Industriales, Universidad Tecnológica de Jalisco, Guadalajara, Jalisco, Mexico.E-mail: jorgearreolav85@gmail.com

$\dagger$ Electronic supplementary information (ESI) available. See DOI: 10.1039/d0ra01849j making it highly recalcitrant for biological attack. ${ }^{6}$ For this reason, a pretreatment step must be implemented to overcome the LCB recalcitrance and achieve an efficient biochemical conversion.

Up to now, different but limited single or combination of physical, chemical, physicochemical and biological pretreatment methods have been used in Agave bagasse. The efficiency and productivity of these studies can be consulted in a review elsewhere. ${ }^{7}$ Specifically, for gaseous biofuels (methane and hydrogen) generation from Agave tequilana bagasse (ATB), only alkaline hydrogen peroxide and dilute acid pretreatments have been implemented, obtaining 0.35 and $0.28 \mathrm{~L} \mathrm{CH}_{4}$ per $\mathrm{g}$ COD (chemical oxygen demand), respectively. ${ }^{\mathbf{8}-10}$

All the pretreatment methods notably alter the chemical and physical structure of lignocellulosic biomass with their specific mode of action, which enhances subsequent saccharification and fermentation steps. ${ }^{\mathbf{1 1}}$ Ionic liquid (IL) pretreatment has been successfully implemented in ATB with promising results to achieve a suitable, efficient and cost-effective technology. ILs are salts with low meting points and favorable solvent properties such as non-flammability, low or negligible vapor pressure, chemical and thermal stability. ${ }^{12}$ The main effects of IL pretreatment on ATB are the partial removal of hemicellulose/ lignin and crystalline cellulose without the generation of inhibitors or cellulose degradation, which entails an efficient saccharification and biofuel generation. ${ }^{\mathbf{1 3}}$ 
To the best of our knowledge, all of the reports regarding IL pretreatment on ATB are imidazolium-based ILs, such as 1ethyl-3-methylimidazolium acetate [Emim] [OAc] ${ }^{14-17}$ 1-butyl-3methylimidazolium chloride $[\mathrm{Bmim}][\mathrm{Cl}]^{18}$ and 1-butyl-3methylimidazolium acetate $[\mathrm{Bmim}][\mathrm{OAc}]{ }^{19}$ However, imidazolium-based ILs are not compatible and exhibit toxicity to enzymes and microbes, making necessary to implement an extensive water wash process to remove the residual IL after pretreatment. Recently, the synthesis of novel ILs from renewable biomaterials, such as the bioderived cholinium ILs have gained attention as new promising approaches due to their biocompatibility. ${ }^{20,21}$

Different reports have demonstrated the potential of cholinium lysinate ([Ch][Lys]) that derives from amino acids as a sustainable and less toxic IL for LCB pretreatment with comparable or higher efficiencies to non-renewable ILs in terms of delignification capability, enhancing the accessibility of polysaccharides to enzymes and retaining effectiveness during reuse. $^{22-25}$

Due to the aforementioned, we aimed to evaluate for the first time the effect of [Ch][Lys] pretreatment on ATB and further methane production via anaerobic digestion. A central composite design (CCD) was employed to optimize the pretreatment conditions followed by in-depth biomass characterization and methane generation from pretreated solids and enzymatic hydrolysates. Briefly, pretreatment conditions (temperature, time and solids loading) were optimized for maximizing sugar production during the saccharification step. Then, recalcitrance parameters (i.e. lignin and crystallinity) were measured in the untreated and IL pretreated biomass to evaluate the effect of pretreatment on the plant cell wall using $\mathrm{X}$ ray diffraction, Fourier transform infrared (FTIR) and confocal fluorescence/scanning electron microscopy. Finally, we provide a mass balance using the optimized pretreatment conditions based on $100 \mathrm{~kg}$ of untreated ATB using the glucan and xylan conversion and methane production by anaerobic digestion.

\section{Experimental}

\section{Experimental design}

A preliminary factorial experimental design was carried out in order to set an adequate solid loading for the further optimization experimental design. Six different IL pretreatment conditions were evaluated based on previous reports of different biomass feedstocks. ${ }^{21,24,26}$ Thus, the ATB was subjected to pretreatment with the renewable IL [Ch][Lys] using a fixed time of $120 \mathrm{~min}$, two temperatures $\left(120{ }^{\circ} \mathrm{C}\right.$ and $\left.140{ }^{\circ} \mathrm{C}\right)$ and three solids loading $(10,20$ and $30 \%)$. The main response variable was the sugar yield [g total sugars (TS) per g ATB] obtained during the enzymatic saccharification of pretreated solids (Table 1).

Optimization of the temperature and reaction time of the IL pretreatment to maximize sugar yield during enzymatic hydrolysis was carried out by CCD as reported elsewhere. ${ }^{17}$ In this second design, the solids loading was set at $20 \%$ since it was the best condition found during the preliminary experimental design (Table 1). Therefore, the CCD consisted on 4 factorial, 3
Table 1 Experimental data from the preliminary runs of [Ch][Lys]pretreatment

\begin{tabular}{|c|c|c|c|c|}
\hline Run & Condition & $\begin{array}{l}\% \text { Solids } \\
\text { recovery }\end{array}$ & $\begin{array}{l}\text { Total sugars } \\
(\mathrm{g} \text { TS L }\end{array}$ & $\begin{array}{l}\text { \% Sugar } \\
\text { yield ( } \mathrm{g} \text { TS per g ATB) }\end{array}$ \\
\hline A & $140{ }^{\circ} \mathrm{C}, 10 \%$ & 56.7 & $38.9 \pm 0.7$ & $44.9 \pm 0.2$ \\
\hline B & $140{ }^{\circ} \mathrm{C}, 20 \%$ & 67.9 & $38.8 \pm 0.8$ & $53.8 \pm 0.2$ \\
\hline $\mathrm{C}$ & $140{ }^{\circ} \mathrm{C}, 30 \%$ & 78.4 & $29.4 \pm 0.1$ & $48.3 \pm 0.1$ \\
\hline $\mathrm{D}$ & $120{ }^{\circ} \mathrm{C}, 10 \%$ & 62.2 & $32.8 \pm 0.2$ & $42.9 \pm 0.2$ \\
\hline $\mathrm{E}$ & $120{ }^{\circ} \mathrm{C}, 20 \%$ & 71.6 & $33.5 \pm 0.6$ & $51.0 \pm 0.6$ \\
\hline $\mathrm{F}$ & $120{ }^{\circ} \mathrm{C}, 30 \%$ & 77.0 & $27.0 \pm 0.6$ & $44.3 \pm 0.4$ \\
\hline
\end{tabular}

central and 4 axial points (Table 2); the data was analyzed using the Statgraphics Centurion XV software including the response surface plotting.

\section{Materials and sample preparation}

ATB was received from a tequila factory located in Jalisco, Mexico denominated Casa Herradura. In brief, after removing all leaves from the Agave in a traditional tequila process, the Agave stems are cooked during $24 \mathrm{~h}$ at $90-100^{\circ} \mathrm{C}$ in a brick oven, milled and pressed to separate the liquid fraction (must) used for spirits production, while the solid fraction (bagasse) is used for the purpose of this study. A washing step was performed in ATB to remove any possible residual sugars, sun-dried for 3 days and particle reduced in a Pulvex mill (Pulvex Plastic, Mexico City, Mexico) equipped with a 20-mesh screen sieve and stored at $4{ }^{\circ} \mathrm{C}$ before use. The ionic liquid cholinium lysinate ([Ch] [Lys)] was prepared and characterized as described in ESI Fig. S1. $\dagger$

\section{Ionic liquid (IL)-based pretreatment}

ATB samples were pretreated with [Ch][Lys] at the desired process conditions [solids loading $(\% \mathrm{w} / \mathrm{w})$, temperature $\left({ }^{\circ} \mathrm{C}\right)$ and reaction time $(\mathrm{h})]$ accordingly to the corresponding design. Each pretreatment run was carried out in a convection oven where IL and ATB solids (in dry basis) were mixed to generate a slurry in a $250 \mathrm{~mL}$ glass reactor, then heated to the temperature and time selected.

After pretreatment, a washing stage was carried out to remove lignin and IL; the pretreated solids were recovered as previously described..$^{15}$

\section{Enzymatic saccharification}

Saccharification of raw and IL-pretreated ATB were performed using $4 \%$ solids loading in $50 \mathrm{mM}$ citrate buffer at $\mathrm{pH} 4.8$. Commercial enzymatic cocktail from Novozymes, CTec 2 with an activity of 161 FPU per mL was employed. An enzymatic loading equivalent to $8 \mathrm{FPU}$ per $\mathrm{g}$ solids was used for the runs of the experimental designs. The reaction conditions were set at $50{ }^{\circ} \mathrm{C}$ and $150 \mathrm{rpm}$ during $72 \mathrm{~h}$ in a rotary incubator.

All assays were performed in duplicate and the sugar production was followed by sampling $1 \mathrm{~mL}$ at $0,1,2,4,8,24,48$ and $72 \mathrm{~h}$. 


\section{Anaerobic digestion experiments}

The inoculum employed (anaerobic granular sludge) was obtained from a full-scale up-flow anaerobic sludge blanket (UASB) reactor treating tequila vinasses. Batch assays were carried out using an inoculum concentration of $10 \mathrm{~g} \mathrm{~L}^{-1}$ of volatile solids (VS).

All reactions were performed in an automatic methane potential test system (AMPTS II, Bioprocess Control, Lund, Sweden) that consists of fifteen single $0.5 \mathrm{~L}$ reactors, each one with their individual mixing motor, $\mathrm{CO}_{2}$ elimination unit and $\mathrm{CH}_{4}$ flow measurement cell. During the experimental runs, the temperature, pressure and accumulated gas volume were recorded automatically by the AMPTS II system; at the end of the process a report was generated with normalized values of flow and accumulated gas.

These experiments were carried out at $37^{\circ} \mathrm{C}$, with an agitation of $60 \mathrm{rpm}$ and a $360 \mathrm{~mL}$ working volume supplemented with the substrate and a mineral medium adjusted to $\mathrm{pH} 8$ as previously reported by Arreola-Vargas et al. ${ }^{9}$ The substrate for the anaerobic digestion experiments were: enzymatic hydrolysates obtained from saccharification of pretreated ATB at a concentration of $5 \mathrm{~g}$ TS $\mathrm{L}^{-1}$ and the pretreated ATB solids at $5 \mathrm{~g} \mathrm{VS} \mathrm{L}{ }^{-1}$ (both obtained at optimal [Ch][Lys]-pretreatment conditions); comparison with untreated ATB solids was evaluated. Experiments were carried out in triplicate.

\section{Analytical methods}

The main cell wall components (cellulose, hemicellulose and lignin) of raw and pretreated ATB were determined using a semiautomatic fiber analyzer (ANKOM Technology, Macedon, NY, USA). ${ }^{27}$ TS in the enzymatic hydrolysates were measured as reported by DuBois et al. ${ }^{28}$ and monosaccharides were determined as previously reported. ${ }^{17}$

Volatile solids from ATB and granular sludge were determined according to standard methods. ${ }^{10}$ The chemical oxygen demand (COD) was obtained using the standard method of APHA 5220 using vials TNT 822 in a DRB200 digester and a DR2800 spectrophotometer. ${ }^{\mathbf{1 0}}$ Attenuated total reflectance (ATR)-FTIR and X-ray powder diffraction (XRD) patterns of untreated and pretreated samples were obtained as previously reported. ${ }^{17}$ Crystallinity index (CrI) were determined according to Segal et al.: ${ }^{29}$

$$
\operatorname{CrI}(\%)=\frac{I_{\text {total }}-I_{\mathrm{am}}}{I_{\text {total }}} \times 100
$$

Finally, morphology of raw and IL-pretreated samples were analyzed by scanning electron and confocal fluorescence microscopy as reported by Avila-Lara et al. ${ }^{\mathbf{3 0}}$

All the statistical analysis were carried out by using Statgraphics Centurion XV software.

\section{Results and discussion}

\section{Effect of solids loading on sugar pretreatment}

In order to build an adequate and precise design to carry out the pretreatment optimization, preliminary experimental runs at different solids loadings, two temperatures and at a fixed time of 120 min were evaluated in terms of sugar yield.

Table 1 shows that in both temperatures, an increase in the solids recovery was attained accordingly to the solids loading during pretreatment from 10 to $30 \%$. A similar effect was reported for the pretreatment of corn stover at $140{ }^{\circ} \mathrm{C}$ with [Ch][Lys], in which the solids loading at $50 \%(\mathrm{w} / \mathrm{w})$ generated a solids recovery of $65 \%$ while at $15 \%$ a recovery of $46 \%$ was obtained. ${ }^{23}$

Regarding sugar release during saccharification, Fig. 1 shows that the two highest TS concentrations were accomplished at $140{ }^{\circ} \mathrm{C}$, where the solids loading factor did not have a significant effect. However, at a solids loading of $30 \%$, the concentration of sugars in the hydrolysate decreased for both temperatures to $27.0 \mathrm{~g}$ $\mathrm{TS} \mathrm{L}^{-1}\left(120^{\circ} \mathrm{C}\right)$ and $29.4 \mathrm{~g} \mathrm{TS} \mathrm{L}^{-1}\left(140{ }^{\circ} \mathrm{C}\right)$. Thus, the best sugar yield was obtained in experimental run B at a solids loading of $20 \%$, achieving $53.8 \mathrm{~g} \mathrm{TS} \mathrm{g}^{-1}$ ATB (Table 1). Interestingly, this sugar yield is similar to the optimum one found in a recent report with [Emim] [OAc] (52.1 $\mathrm{g}^{\mathrm{TS} \mathrm{g}^{-1}} \mathrm{ATB}$ at $120{ }^{\circ} \mathrm{C}, 120 \mathrm{~min}$ and $30 \%$ solids loading) $;{ }^{17}$ however, the pretreatment conditions are different. In this sense, the experimental run $\mathrm{F}$ shows that at the same optimal [Emim][OAc]-pretreatment conditions, the renewable IL [Ch][Lys] produced a lower sugar yield of $44.3 \%$. Therefore, it is clear that the chemical nature of each specific IL generates different responses.

\section{Optimization of the pretreatment conditions}

From the proposed CCD design, 11 experimental conditions were evaluated including 3 central points for measuring the

Table 2 Experimental data from pretreated ATB using [Ch][Lys] at different pretreatment conditions from the CCD

\begin{tabular}{|c|c|c|c|c|c|c|}
\hline Run & Condition & $\begin{array}{l}\% \text { Solids } \\
\text { recovery }\end{array}$ & $\begin{array}{l}\text { Total sugars } \\
\left(\mathrm{g}^{\mathrm{TS} \mathrm{L}} \mathrm{L}^{-1}\right)\end{array}$ & $\begin{array}{l}\text { \% Sugar } \\
\text { yield (g TS per g ATB) }\end{array}$ & \% Glucan conversion & \% Xylan conversion \\
\hline 1 & $120^{\circ} \mathrm{C}, 60 \mathrm{~min}$ & 78.4 & $29.1 \pm 0.0$ & $47.0 \pm 0.5$ & $66.7 \pm 0.8$ & $68.2 \pm 0.4$ \\
\hline 2 & $160^{\circ} \mathrm{C}, 60 \mathrm{~min}$ & 70.0 & $36.3 \pm 0.1$ & $52.3 \pm 0.1$ & $74.8 \pm 0.1$ & $73.7 \pm 0.2$ \\
\hline 3 & $120^{\circ} \mathrm{C}, 180 \mathrm{~min}$ & 71.0 & $35.2 \pm 0.5$ & $51.7 \pm 0.1$ & $73.9 \pm 0.1$ & $73.4 \pm 0.1$ \\
\hline 4 & $160{ }^{\circ} \mathrm{C}, 180 \mathrm{~min}$ & 113.4 & $15.0 \pm 0.4$ & $34.7 \pm 0.4$ & $50.0 \pm 0.7$ & $47.5 \pm 1.6$ \\
\hline CP1 & $140^{\circ} \mathrm{C}, 120 \mathrm{~min}$ & 67.9 & $38.8 \pm 0.8$ & $53.8 \pm 0.2$ & $79.9 \pm 0.7$ & $65.9 \pm 3.6$ \\
\hline $\mathrm{CP} 2$ & $140{ }^{\circ} \mathrm{C}, 120 \mathrm{~min}$ & 69.4 & $37.2 \pm 0.1$ & $52.6 \pm 0.2$ & $75.3 \pm 0.3$ & $73.8 \pm 0.7$ \\
\hline CP3 & $140{ }^{\circ} \mathrm{C}, 120 \mathrm{~min}$ & 68.9 & $36.3 \pm 0.1$ & $51.3 \pm 0.1$ & $74.0 \pm 0.8$ & $70.1 \pm 1.8$ \\
\hline $1 \mathrm{~A}$ & $112{ }^{\circ} \mathrm{C}, 120 \mathrm{~min}$ & 76.4 & $28.8 \pm 0.5$ & $46.2 \pm 0.9$ & $67.3 \pm 1.4$ & $60.9 \pm 1.0$ \\
\hline $2 \mathrm{~A}$ & $168{ }^{\circ} \mathrm{C}, 120 \mathrm{~min}$ & 151.3 & $6.8 \pm 0.0$ & $21.4 \pm 0.0$ & $33.2 \pm 0.1$ & $21.4 \pm 0.0$ \\
\hline $3 \mathrm{~A}$ & $140{ }^{\circ} \mathrm{C}, 35 \mathrm{~min}$ & 73.7 & $33.2 \pm 0.3$ & $50.0 \pm 0.4$ & $71.3 \pm 0.6$ & $71.4 \pm 0.4$ \\
\hline $4 \mathrm{~A}$ & $140{ }^{\circ} \mathrm{C}, 205 \mathrm{~min}$ & 71.7 & $36.2 \pm 0.1$ & $52.4 \pm 0.1$ & $76.8 \pm 0.6$ & $67.5 \pm 1.3$ \\
\hline
\end{tabular}




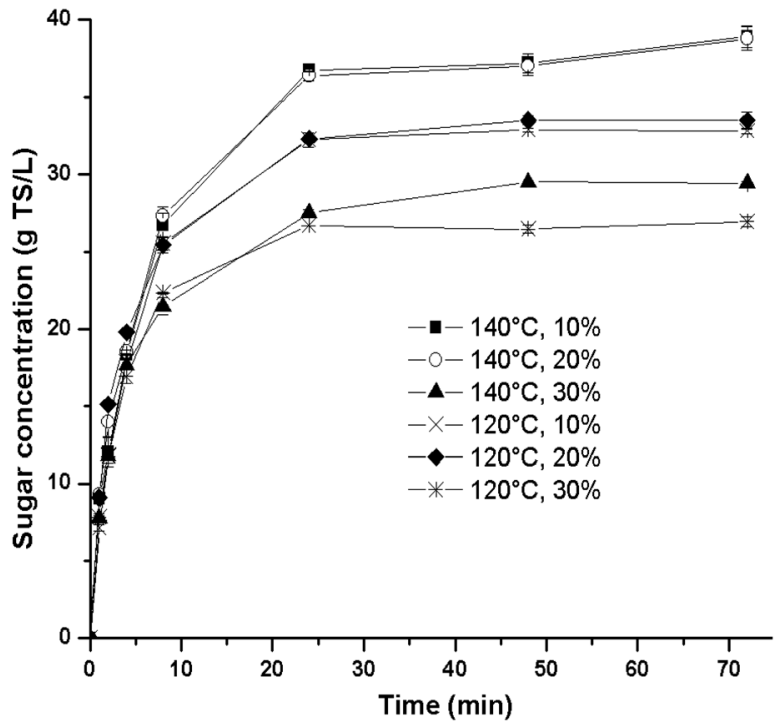

Fig. 1 Kinetic profiles of sugar concentration obtained from the first experimental design at different conditions of temperature and solids loading.

experimental error (Table 2). The solids loading was fixed at $20 \%$.

According to the nature of the CCD design, the runs of the $2^{\mathrm{k}}$ factorial design along with the central points were firstly executed and once lack of fit to a linear model was found $(p=$ 0.0227), the axial points were added to fit the data to a second order model and find an optimal response. ${ }^{17}$

Interestingly, a special phenomenon occurred under conditions 4 and $2 \mathrm{~A}$ where solid recoveries surpassed $100 \%$. This suggests that solid compounds were formed from [Ch][Lys] due to the high pretreatment temperatures $\left(160^{\circ} \mathrm{C}\right.$ and $\left.168^{\circ} \mathrm{C}\right)$. The [Ch][Lys] decomposition temperature is $168{ }^{\circ} \mathrm{C}$ but some studies suggest that ILs decomposition occur at temperatures close to the decomposition one. ${ }^{31,32}$ According to this information, a hypothesis could be formulated in which the combination of a long reaction time (180 $\mathrm{min})$ with the temperature of $160{ }^{\circ} \mathrm{C}$, generated a lower thermostability of [Ch][Lys], causing its degradation in solid compounds that impacted the recovery of solids. Apparently, this did not happen with a lower reaction time of $60 \mathrm{~min}$, since their recovery of solids $(70 \%)$ and concentration of sugars during saccharification $\left(36.3 \mathrm{~g}^{\mathrm{TS} \mathrm{L}}{ }^{-1}\right)$ are similar to the best condition of the design $\left(120^{\circ} \mathrm{C}\right.$ and 180 $\min$ ) with $71 \%$ and $35.2 \mathrm{~g} \mathrm{TS} \mathrm{L}^{-1}$, respectively.

The ANOVA of the CCD indicated that the significant factors of the design were the temperature and the quadratic factor of temperature, with a statistical confidence of $95 \%$ (data not shown). The time did not significantly influence the TS yield for the intervals that were evaluated in the design, which can be confirmed in Fig. 2. However, in the response surface plot from Fig. 2, it can also be clearly observed that at low temperatures (such as $120^{\circ} \mathrm{C}$ ), the TS yield is being favored as the reaction time increases. In this sense, Hou et al., showed that for rice straw [Ch][Lys]-pretreatment at $90{ }^{\circ} \mathrm{C}$, when the pretreatment time was greater than $5 \mathrm{~h}$, its effect on enzymatic
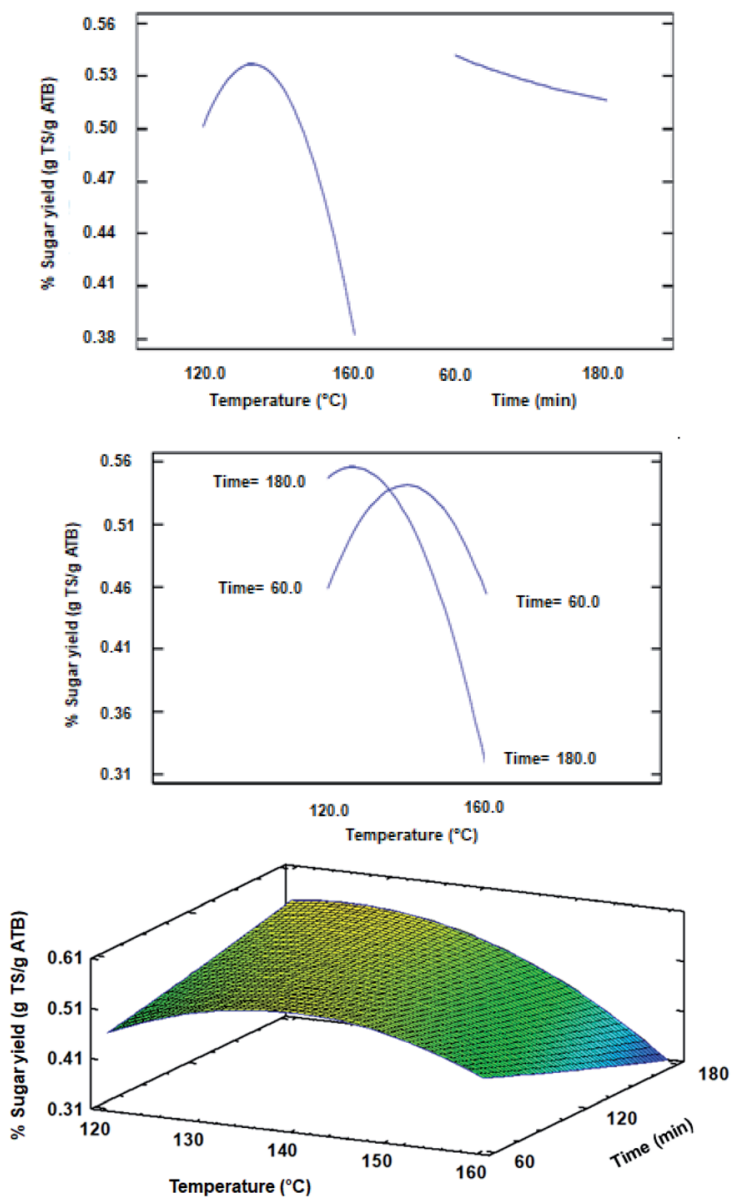

Fig. 2 Main effect (top), interaction (middle) and response surface (bottom) plots obtained for CCD evaluating the temperature and time effects on sugar yield.

saccharification decreased although the extraction of lignin was improved. ${ }^{22}$ A similar effect could have happened during the conditions evaluated in the current experimental design, taking into consideration that a similar pretreatment severity with relatively high temperatures (greater than $90{ }^{\circ} \mathrm{C}$ ) and short residence times (less than $180 \mathrm{~min}$ ) could have generated a similar effect to the one reported by Hou et al. ${ }^{22}$

As regards to the optimal conditions for the pretreatment, the most suitable regression model obtained by eliminating non-significant terms with an $R$-square of 0.9780 is shown in the following equation:

$$
Y=0.0101991 X-0.0000482869 X^{2}
$$

where $Y$ represents the yield of total sugars ( $\mathrm{g}$ TS per $\mathrm{g}$ ATB) and $X$ the temperature. The optimal pretreatment conditions determined by the model are a temperature of $124{ }^{\circ} \mathrm{C}$ and a reaction time of $205 \mathrm{~min}$. Similarly to [Emim][OAc]pretreatment, the mild conditions in ATB to maximize sugar production contrast with the typically harsher conditions (140$160{ }^{\circ} \mathrm{C}$ ) applied in other feedstocks such as corn stover or switchgrass that ultimately must be taken into consideration in the total production costs in a biorefinery scheme. ${ }^{23,33}$ 
Effects of pretreatment on the Agave tequilana bagasse (ATB) cell wall composition and structure

The main constituents of the plant cell wall of ATB were glucan (54.4\%), xylan (15.7\%) and lignin (12.1\%). While ATB was consistent with previous reports in terms of xylan and lignin, the glucan content was relatively high, which can be attributed to the environmental conditions and post-harvest procedures including the cooking conditions during tequila production. ${ }^{34}$

According to the optimal conditions obtained in the preceding subsection, [Ch][Lys]-pretreatment of ATB was carried out. The solids recovery from the pretreated biomass was $75.0 \%$ with a composition of $68.9 \%$ glucan, $18.0 \%$ xylan and $8.8 \%$ lignin. Thus, the main observed changes in the cell wall composition of pretreated ATB were an increase in glucan/ xylan content and lignin removal. Taking into consideration the solid recovery, the delignification obtained was $45.4 \%$, demonstrating the high capacity for the removal of lignin. In addition, the removal of lignin by [Ch][Lys] is due to the anion lysinate, whose delignification capacity is favored when a temperature higher than $90{ }^{\circ} \mathrm{C}$ is used. ${ }^{35}$

The chemical changes after pretreatment were followed by seven FTIR bands of carbohydrate and lignin plus two bands related to calcium oxalate. According to Fig. 3 and ESI Table S1, $\uparrow$ a minimal change in the band of amorphous cellulose (900 $\mathrm{cm}^{-1}$ ) occurred, possibly due to a slight modification on cellulose crystallinity. Simultaneously, a strong effect on the $\mathrm{C}-\mathrm{O}$ stretching in lignin and hemicellulose $\left(1235 \mathrm{~cm}^{-1}\right)$ due to the relatively high lignin removal occurred after pretreatment. ${ }^{36}$ Furthermore, an elevated increment to $68.1 \%$ in the $1745 \mathrm{~cm}^{-1}$ band [carbonyl $(\mathrm{C}=\mathrm{O})$ stretching] indicate cleavage of lignin and side chains were obtained. In addition, a reduction in the intensities of the bands 2900 and $3348 \mathrm{~cm}^{-1}$ occurred in the pretreated ATB when compared to the untreated solids, which could indicate a contraction of the $\mathrm{C}-\mathrm{H}$ and $\mathrm{O}-\mathrm{H}$ linkages that contrast with other pretreatments such as lime or dilute acid. ${ }^{37}$

A significant reduction in the band positions attributed to calcium oxalate at $1321 \mathrm{~cm}^{-1}$ and more noticeable at $1622 \mathrm{~cm}^{-1}$ was obtained in the [Ch][Lys]-pretreated ATB, which is higher than the changes obtained with [Emim] [OAc]-pretreated ATB. ${ }^{34}$

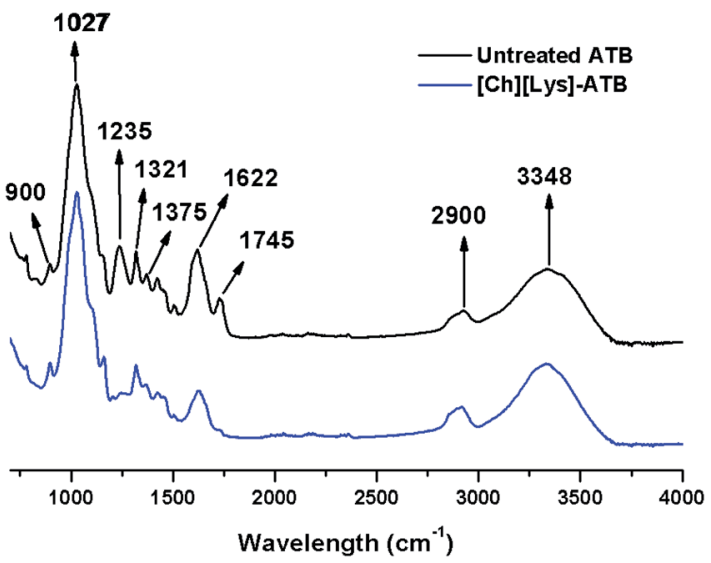

Fig. 3 Chemical changes in ATB solids (untreated and IL-pretreated) determined by FTIR-ATR.
In addition, the cellulose crystallinity index (CrI) is an important parameter to evaluate the response on enzymatic saccharification.

The powder XRD patterns of untreated and [Ch][Lys]pretreated ATB are shown in ESI Fig. S2. $\uparrow$ The CrI values of untreated and IL-pretreated ATB were 0.51 and 0.62 , respectively. It is noticeable, that unlike imidazolium-based IL pretreatment in ATB, where a reduction of cellulose crystallinity occurred, an increase in the CrI values were attained..$^{15,17}$ This effect of increasing the CrI after the [Ch][Lys] pretreatment of LCB has been previously reported and was attributed to the removal of the amorphous cell wall components such as lignin and hemicellulose. ${ }^{21,22}$ Finally, scanning electron and confocal fluorescence microscopy high-resolution images from untreated and [Ch][Lys]-pretreated ATB are shown in ESI Fig. S3 and $\mathrm{S} 4, \uparrow$ respectively. It can be observed in ESI Fig. $\mathrm{S} 3 \uparrow$ that after pretreatment the samples have swollen structures, with broken fibers including amorphous and irregular parts. This causes an increase in the surface area that has been reported as positive in the pretreatment of rice straw using [Ch][Lys] mixed with water. $^{38}$ The phenomenon of LCB structure swelling could be due to the breakdown of the lignin-carbohydrate bonds, which occurs after lignin removal during the dissolution and regeneration process of the cellulose. ${ }^{34}$ Besides, calcium oxalate monohydrate crystals were found in untreated and [Ch][Lys]pretreated (ESI Fig. S3†).

The oxalate crystals found in the BAT have a prismatic and regular shape while those of the [Ch][Lys]-pretreated ATB are prisms with irregular structure and rounded tips. The formation of spherical crystals can be an effect of the IL pretreatment and this tendency increases the greater the severity of the pretreatment. ${ }^{39}$ Additionally, the elemental composition (using EDS) that was obtained for the oxalate crystals in the ATB and [Ch][Lys]-pretreated ATB are similar to each other and approximates to the theoretical value obtained by the compound formula (ESI Table $\mathrm{S} 2 \dagger$ ).

In the ESI Fig. $\mathrm{S} 4 \uparrow$ is presented the micrographs taken by confocal microscopy of the untreated and [Ch][Lys]-pretreated ATB in which distinctive fluorescence intensities are observed for lignin (blue), cellulose (green) and hemicellulose (red). Interestingly, minor delignification was observed in the pretreated solids with [Ch][Lys].

This could be attributed to the fact that pretreatment with [Ch][Lys] generated a swelling effect and an increase in the surface area of lignin, which caused this component to visually appear a greater presence in the lignocellulosic matrix when in fact a considerable part of the lignin was removed by the action of the pretreatment. ${ }^{17,34}$

\section{Methane production from enzymatic hydrolysates and pretreated solids obtained at optimal pretreatment conditions}

Anaerobic digestion is an attractive process for the production of gaseous biofuels because it is carried out by microbial communities, which present a high diversity of metabolic pathways and in turn provide robustness to the process. ${ }^{40}$ However, the metabolic capacity of these communities is 
insufficient to efficiently incorporate the nutrients that make up the ATB without pretreatment.

Due to the fact that IL pretreatment modify the lignocellulosic structure making it less recalcitrant and more accessible to the microbial degradation, during the anaerobic digestion assays not only the enzymatic hydrolysates but also the solids from the $[\mathrm{Ch}][\mathrm{Lys}]$-pretreated ATB were evaluated as substrates.

Fig. 4 shows the kinetic profiles for methane production from enzymatic hydrolysates and pretreated ATB solids (both obtained at optimal [Ch][Lys]-pretreatment conditions); the methane production from the untreated ATB is also shown for comparison purposes. It is clearly noticeable that the hydrolysate achieved the highest accumulation of methane up to $613 \mathrm{~mL}$ with a yield of $0.30 \mathrm{~L} \mathrm{CH}_{4}$ per $\mathrm{g}$ COD $(86 \%$ of the theoretical maximum yield of $0.35 \mathrm{~L} \mathrm{CH}_{4}$ per $\mathrm{COD}$ ), whereas the lowest methane was produced by the untreated ATB reaching only $80 \mathrm{~mL}$ and a yield of $0.04 \mathrm{~L} \mathrm{CH}_{4}$ per COD. The methane yield obtained with this type of hydrolysates is similar to other reports using specialized reactors or similar hydrolysates. ${ }^{\mathbf{4 1 , 4 2}}$

Interestingly, the $[\mathrm{Ch}][\mathrm{Lys}]$-pretreated solids without being saccharified reached $433 \mathrm{~mL}$ of methane with a yield of $0.24 \mathrm{~L}$ $\mathrm{CH}_{4}$ per VSS, representing a 5.4 fold compared to the untreated ATB and a $70 \%$ of the methane produced by the hydrolysate; making clear that the availability of the nutrients contained in the ATB increases considerably through pretreatment with ILs.

It is important to mention that the values reported for methane production were calculated by subtracting the values obtained with the endogenous and enzyme controls in order to eliminate the contribution of COD from the inoculum and the enzyme to the process as previously reported. ${ }^{9}$ Even though the [Ch][Lys]-pretreated solids generated a lower amount of methane compared to the hydrolysate and also a lower methane production rate was observed (0.09 vs. $0.43 \mathrm{~L} \mathrm{CH}_{4}$ per L per d), the scarce reports on anaerobic digestion using IL pretreated LCB solids (Table 3) show that the reported yield in this work is the highest reported so far with a value of $0.24 \mathrm{~L} \mathrm{CH}_{4}$ per $\mathrm{g}$ VSS, confirming the potential of both the type of LCB and IL pretreatment. ${ }^{43-45}$

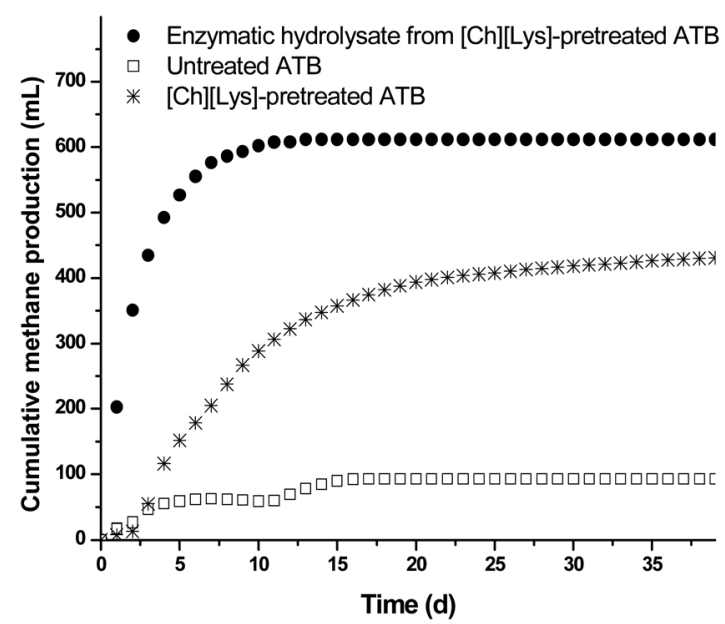

Fig. 4 Methane production kinetics from enzymatic hydrolysate and solids of ATB (untreated and pretreated with [Ch][Lys]).
Table 3 Comparison to reported works on anaerobic digestion of different IL pretreated biomass

\begin{tabular}{llll}
\hline Biomass & IL pretreatment & $\begin{array}{l}\text { Yield (L CH} \\
\text { per g VSS }\end{array}$ & Reference \\
\hline ATB & {$[\mathrm{Ch}][\mathrm{Lys}]$} & $0.24 \pm 0.12$ & This study \\
Water hyacinth & {$[\mathrm{Bmim}][\mathrm{Cl}] / \mathrm{DMSO}^{a}$} & 0.16 & 43 \\
Water hyacinth & {$[\mathrm{Bmim}][\mathrm{Cl}]$} & 0.20 & 44 \\
Grass & {$[\mathrm{Bmim}][\mathrm{OAc}]$} & 0.22 & 45 \\
${ }^{a}$ DMSO: dimethyl sulfoxide. & &
\end{tabular}

Finally, regarding the hydrolysis step during the anaerobic digestion of ATB solids, the degradation of lignocellulose in these systems has been reported to be carried out by microorganisms such as the genus Acetivibrio and Clostridium, ${ }^{\mathbf{4 6}}$ so it is possible that microorganisms of this type have participated in the hydrolysis of [Ch][Lys]-pretreated ATB, since they have been reported in previous works using the same inoculum. ${ }^{41}$

\section{Mass balance of optimized pretreated-Agave tequilana bagasse for methane production}

Based on the optimum pretreatment conditions, hydrolysates from [Ch][Lys]-pretreated ATB were obtained and characterized, presenting high COD (35.4 $\left.\mathrm{g} \mathrm{L}^{-1}\right)$ and concentration of total sugars $\left(32.5 \mathrm{~g} \mathrm{~L}^{-1}\right)$ constituted by $16.1 \mathrm{~g}$ glucose per L, $7.4 \mathrm{~g}$ xylose per $\mathrm{L}$ among others sugars. Noticeable it is the absence of inhibitory compounds for microorganisms such as furfural, hydroxymethylfurfural (HMF), and acetic acid. ${ }^{47}$ It is important to point out that a considerable part of the sugars obtained are pentoses, which represents $22.7 \%$ of the TS in the hydrolysate. The utilization of xylose can be carried out by microorganisms that participate in anaerobic digestion, for which hydrolysates from [Ch][Lys]-pretreated ATB are a potential substrate for this process. $^{48}$

Total sugars production from saccharification of [Ch][Lys]pretreated ATB reached $32.5 \mathrm{~g}$ TS $\mathrm{L}^{-1}$ in $72 \mathrm{~h}$ with a 6.3 -fold increase when compared to the untreated biomass $\left(5.2 \mathrm{~g} \mathrm{TS} \mathrm{L}^{-1}\right)$ and an accelerated kinetics between 10 and $48 \mathrm{~h}$ (data not shown).

This high sugar concentration along with a high yield $(51.4 \mathrm{~g}$ TS per $\mathrm{g}$ ATB) occurred by different reasons. First, a high solids recovery during [Ch][Lys] pretreatment; and second, a high lignin removal $(45.4 \%)$ including the modification of the carbohydrate-lignin linkages as shown by FTIR. However, a high delignification does not always guarantee an efficient enzymatic saccharification. For instance, during the AHP pretreatment of ATB, a higher delignification was achieved (97\%) compared to [Ch][Lys] pretreatment (45.4\%); however, a 3-times lower TS concentration was obtained with AHP pretreated ATB. ${ }^{8}$

In order to establish a mass balance of the bioprocess transformation of ATB into methane to gain a better understanding of [Ch][Lys] pretreatment technology, the compositional analysis, sugar yield, and methane production were normalized into a $100 \mathrm{~kg}$ ATB basis in dry weight (Fig. 5). 


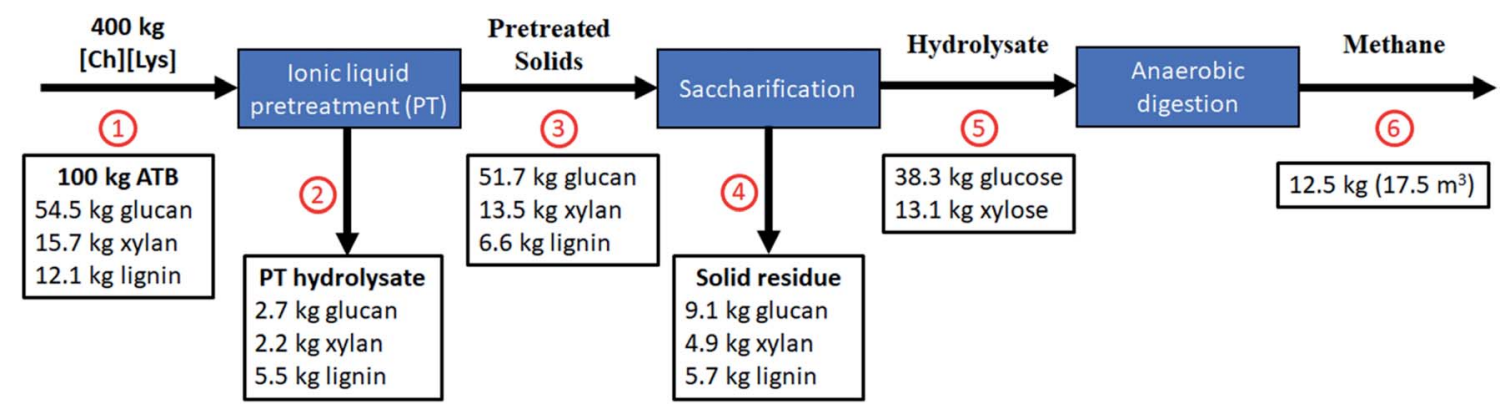

Fig. 5 Mass balance per $100 \mathrm{~kg}$ of untreated ATB in dry weight using optimized pretreatment conditions with high solids loading for sugars and methane production. (1) ATB input; (2) liquid waste from pretreatment; (3) pretreated ATB; (4) non-saccharified solids; (5) enzymatic hydrolysate; (6) methane production.

Using the optimized pretreatment conditions $\left(124{ }^{\circ} \mathrm{C}\right.$, $205 \mathrm{~min}$, and $20 \%$ solids loading), a solid recovery of $75.0 \mathrm{~kg}$ was obtained (including: $51.7 \mathrm{~kg}$ of glucan and $13.5 \mathrm{~kg}$ of xylan) after a water wash step where mostly lignin was solubilized into the liquid stream. These washes have the purpose of removing [Ch][Lys] from the biomass, so it does not interfere during the enzymatic saccharification and it can be recovered for reuse. It has been reported that [Ch][Lys] can be reused up to 5 times, achieving glucose yields higher than $80 \%$, making this stage of the process critical for its economic feasibility. ${ }^{22}$

Moreover, taking into consideration the high recyclability of cholinium based ILs, these chemicals potentially meet environmental requirements for the development of cost-effective IL pretreatment technology in order to reduce up to $70-85 \%$ of greenhouse emissions. ${ }^{25}$

The pretreated solids showed a higher glucan content (51.7 $\mathrm{kg}$ ) with a considerable decrease on lignin from 12.1 to $6.6 \mathrm{~kg}$ when compared to the untreated biomass. After the saccharification step, the optimized pretreated solids reached up to $\sim 51.4$ $\mathrm{kg}$ of sugars per $100 \mathrm{~kg}$ untreated ATB. This sugar yield is higher than our previous reports where [Emim][OAc]-pretreated ATB achieved up to $29.2-44.6 \mathrm{~kg}$ sugars per $100 \mathrm{~kg}$ untreated $\mathrm{ATB}^{4,34}$ or from AFEX-pretreated ATB with $36.2 \mathrm{~kg}$ sugars per $100 \mathrm{~kg}$ untreated ATB. ${ }^{49}$

Additionally, this is the first report that carried out a process mass balance for methane production using ATB. After being anaerobically digested, the $51.4 \mathrm{~kg}$ TS of the enzymatic hydrolysate from [Ch][Lys] pretreated ATB were converted to $17.5 \mathrm{~m}^{3}$ of methane, equivalent to $12.5 \mathrm{~kg} \mathrm{CH}_{4}$ per $100 \mathrm{~kg}$ untreated ATB. Such methane generation represents an energy recovery of $6.27 \mathrm{~kJ} \mathrm{~g}^{-1}$ ATB, which doubles the energy production reported by Arreola-Vargas et al. (2016) by using acid and enzymatic hydrolysates in one stage anaerobic digestion and it is similar to the energy recoveries reported in two-stage anaerobic digestion processes. ${ }^{9}$

\section{Conclusions}

Optimized [Ch][Lys]-pretreated ATB $\left(124{ }^{\circ} \mathrm{C}, 205 \mathrm{~min}, 20 \%\right.$ solids) was able to achieved $51.4 \mathrm{~kg}$ of sugars and $12.5 \mathrm{~kg}$ of $\mathrm{CH}_{4}$ per $100 \mathrm{~kg}$ of untreated biomass due to its relatively high delignification $(45.4 \%)$ and weaken chemical bonds. The highest methane generation was obtained using the hydrolysate from IL-pretreated ATB with a yield of $0.30 \mathrm{~L} \mathrm{CH}_{4}$ per g COD, which is 7.5 times higher when compared to that obtained with the untreated ATB. The pretreated solids were also able to be highly anaerobically digested obtaining a yield of $0.24 \mathrm{~L} \mathrm{CH}_{4}$ per $\mathrm{g}$ VSS, representing a promising approach within a biorefinery scheme since no saccharification is needed. Overall, this study presents an attractive approach to pretreat a residue of great concern in Mexico by applying a potential, economical and environmentally friendly pretreatment that improves the generation of methane.

\section{Conflicts of interest}

There are no conflicts to declare.

\section{Acknowledgements}

This research was supported by the Fund CONACyT-SENERSUSTENTABILIDAD ENERGÉTICA, CEMIE-Bio-Clúster Biocombustibles Gaseosos 247006. The authors thank the Universidad Autónoma de Nayarit for supporting the open access publication of this work.

\section{References}

1 N. Akhtar, K. Gupta, D. Goyal and A. Goyal, Environ. Prog. Sustainable Energy, 2016, 35, 489-511.

2 F. Ahmad, E. L. Silva and M. B. A. Varesche, Renewable Sustainable Energy Rev., 2018, 98, 108-124.

3 CRT, Tequila Regulatory Council, Mexico City, Mexico, Zapopan, Jalisco, 2019, https://www.crt.org.mx/ EstadisticasCRTweb/, accessed 17 June 2018.

4 J. A. Pérez-pimienta, R. M. Mojica-álvarez, L. M. Sánchezherrera and A. Mittal, BioEnergy Res., 2018, 11, 551-561.

5 X. Yan, D. K. Y. Tan, O. R. Inderwildi, J. a. C. Smith and D. a. King, Energy Environ. Sci., 2011, 4, 3110.

6 C. Li, B. Knierim, C. Manisseri, R. Arora, H. V. Scheller, M. Auer, K. P. Vogel, B. A. Simmons and S. Singh, Bioresour. Technol., 2010, 101, 4900-4906.

7 J. A. Pérez-Pimienta, M. G. López-Ortega and A. Sanchez, Biofuels, Bioprod. Biorefin., 2017, 11, 732-748. 
8 K. L. Galindo-Hernández, A. Tapia-Rodríguez, F. AlatristeMondrag, L. B. Celis, J. Arreola-Vargas and E. Razo-Flores, Int. J. Hydrogen Energy, 2018, 43, 22116-22125.

9 J. Arreola-Vargas, A. Flores-Larios, V. González-Álvarez, R. I. Corona-González and H. O. Méndez-Acosta, Int. J. Hydrogen Energy, 2016, 41, 897-904.

$10 \mathrm{~J}$. Arreola-Vargas, V. Ojeda-Castillo, R. Snell-Castro, R. I. Corona-González, F. Alatriste-Mondragón and H. O. Méndez-Acosta, Bioresour. Technol., 2015, 181, 191199.

11 S. P. S. Chundawat, G. T. Beckham, M. E. Himmel and B. E. Dale, Annu. Rev. Chem. Biomol. Eng., 2011, 2, 121-145.

12 P. Halder, S. Kundu, S. Patel, A. Setiawan, R. Atkin, R. Parthasarthy, J. Paz-Ferreiro, A. Surapaneni and K. Shah, Renewable Sustainable Energy Rev., 2019, 105, 268-292.

13 Q. Hou, M. Ju, W. Li, L. Liu, Y. Chen and Q. Yang, Molecules, 2017, 22, 490.

14 M. Equihua-Sánchez and L. F. Barahona-Pérez, Waste Biomass Valorization, 2017, 10, 1285-1294.

15 J. A. Perez-Pimienta, M. G. Lopez-Ortega, P. Varanasi, V. Stavila, G. Cheng, S. Singh and B. A. Simmons, Bioresour. Technol., 2013, 127, 18-24.

16 J. A. Perez-Pimienta, C. A. Flores-Gómez, H. A. Ruiz, N. Sathitsuksanoh, V. Balan, L. da Costa Sousa, B. E. Dale, S. Singh and B. A. Simmons, Bioresour. Technol., 2016, 211, 216-223.

17 J. A. Pérez-Pimienta, J. P. A. Icaza-Herrera, J. A. MéndozaPérez, V. González-Álvarez, H. O. Méndez-Acosta and J. Arreola-Vargas, Bioresour. Technol., 2019, 275, 78-85.

18 J. A. Perez-Pimienta, H. M. Poggi-Varaldo, T. Ponce-Noyola, A. C. Ramos-Valdivia, J. A. Chavez-Carvayar, V. Stavila and B. A. Simmons, Biomass Bioenergy, 2016, 91, 48-55.

19 J. A. Perez-Pimienta, N. Sathitsuksanoh, V. S. Thompson, K. Tran, T. Ponce-Noyola, V. Stavila, S. Singh and B. A. Simmons, Biotechnol. Biofuels, 2017, 10, 72.

20 X. D. Hou, N. Li and M. H. Zong, ACS Sustainable Chem. Eng., 2013, 1, 519-526.

21 T. Dutta, G. Papa, E. Wang, J. Sun, N. G. Isern, J. R. Cort, B. A. Simmons and S. Singh, ACS Sustainable Chem. Eng., 2018, 6, 3079-3090.

22 X. D. Hou, T. J. Smith, N. Li and M. H. Zong, Biotechnol. Bioeng., 2012, 109, 2484-2493.

23 G. Papa, T. Feldman, K. L. Sale, F. Adani, S. Singh and B. A. Simmons, Bioresour. Technol., 2017, 241, 627-637.

24 E. Liu, M. Li, L. Das, Y. Pu, T. Frazier, B. Zhao, M. Crocker, A. J. Ragauskas and J. Shi, ACS Sustainable Chem. Eng., 2018, 6, 6612-6623.

25 B. Neupane, N. V. S. N. M. Konda, S. Singh, B. A. Simmons and C. D. Scown, ACS Sustainable Chem. Eng., 2017, 5, 10176-10185.

26 X. D. Hou, N. Li and M. H. Zong, Bioresour. Technol., 2013, 136, 469-474.

27 P. J. Van Soest, J. B. Robertson and B. A. Lewis, J. Dairy Sci., 1991, 74, 3583-3597.

28 M. DuBois, K. A. Gilles, J. K. Hamilton, P. A. Rebers and F. Smith, Anal. Chem., 1956, 28, 350-356.
29 L. Segal, J. J. Creely, A. E. Martin and C. M. Conrad, Text. Res. J., 1959, 29, 786-794.

30 A. I. Ávila-Lara, J. N. Camberos-Flores, J. A. Mendoza-Pérez, S. R. Messina-Fernández, C. E. Saldaña-Duran, E. I. Jimenez-Ruiz, L. M. Sánchez-Herrera and J. A. PérezPimienta, Front. Bioeng. Biotech., 2015, 3-146, 1-10.

31 Y. Cao and T. Mu, Ind. Eng. Chem. Res., 2014, 53, 8651-8664. 32 R. E. Del Sesto, T. M. McCleskey, C. Macomber, K. C. Ott, A. T. Koppisch, G. A. Baker and A. K. Burrell, Thermochim. Acta, 2009, 491, 118-120.

33 J. Shi, K. W. George, N. Sun, W. He, C. Li, V. Stavila, J. D. Keasling, B. A. Simmons, T. S. Lee and S. Singh, BioEnergy Res., 2015, 8, 1004-1013.

34 J. A. Pérez-Pimienta, A. Vargas-Tah, K. M. López-Ortega, Y. N. Medina-López, J. A. Mendoza-Pérez, S. Avila, S. Singh, B. A. Simmons, I. Loaces and A. Martinez, Bioresour. Technol., 2017, 225, 191-198.

35 N. Sun, R. Parthasarathi, A. M. Socha, J. Shi, S. Zhang, V. Stavila, K. L. Sale, B. A. Simmons and S. Singh, Green Chem., 2014, 16, 2546-2557.

36 C. Li, G. Cheng, V. Balan, M. S. Kent, M. Ong, S. P. S. Chundawat, L. daCosta Sousa, Y. B. Melnichenko, B. E. Dale, B. A. Simmons and S. Singh, Bioresour. Technol., 2011, 102, 6928-6936.

37 R. Kumar, G. Mago, V. Balan and C. E. Wyman, Bioresour. Technol., 2009, 100, 3948-3962.

38 X. D. Hou, N. Li and M. H. Zong, Biotechnol. Bioeng., 2013, 110, 1895-1902.

39 J. A. Perez-Pimienta, M. G. Lopez-Ortega, J. A. ChavezCarvayar, P. Varanasi, V. Stavila, G. Cheng, S. Singh and B. A. Simmons, Biomass Bioenergy, 2015, 75, 180-188.

40 R. I. Amann, W. Ludwig and K.-H. Schleifer, Microbiol. Rev., 1995, 59, 143-169.

41 L. Breton-Deval, H. O. Méndez-Acosta, V. González-Álvarez, R. Snell-Castro, D. Gutiérrez-Sánchez and J. Arreola-Vargas, J. Environ. Manage., 2018, 224, 156-163.

42 R. Snell-Castro, H. O. Méndez-Acosta, J. Arreola-Vargas, V. González-Álvarez, M. Pintado-González, M. T. GonzálezMorales and J. Godon, J. Appl. Microbiol., 2019, 126, 16181630.

43 J. Gao, L. Chen, Z. Yan and L. Wang, Bioresour. Technol., 2013a, 132, 361-364.

44 J. Gao, L. Chen, K. Yuan, H. Huang and Z. Yan, Bioresour. Technol., 2013b, 150, 352-358.

45 W. Li and G. Xu, Environ. Technol., 2016, 38, 1843-1851.

46 W. S. Adney, C. J. Rivard, M. Shiang and M. E. Himmel, Appl. Biochem. Biotechnol., 1991, 30, 165-183.

47 L. J. Jönsson and C. Martín, Bioresour. Technol., 2016, 199, 103-112.

48 F. Monlau, A. Barakat, E. Trably, C. Dumas, J.-P. Steyer and H. Carrère, Crit. Rev. Environ. Sci. Technol., 2013, 43, 260322.

49 C. A. Flores-gómez, E. M. Escamilla Silva, C. Zhong, B. E. Dale, L. Da, C. Sousa and V. Balan, Biotechnol. Biofuels, 2018, 11, 1-18. 